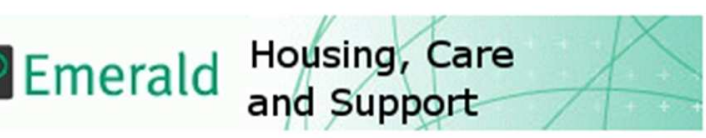

\title{
OUTCOMES-BASED COMMISSIONING FOR SOCIAL CARE IN EXTRA CARE HOUSING: IS THERE A FUTURE?
}

\begin{tabular}{|r|l|}
\hline Journal: & Housing, Care and Support \\
\hline Manuscript ID & HCS-03-2017-0003.R2 \\
\hline Manuscript Type: & Policy Analysis \\
\hline Keywords: & $\begin{array}{l}\text { Commissioning, Extra Care Housing, Social Care, Older People, Outcomes } \\
\text { Based Commissioning, Supported Housing }\end{array}$ \\
\hline \multicolumn{2}{|l}{} \\
\hline
\end{tabular}

\section{SCHOLARONE ${ }^{\text {m }}$ \\ Manuscripts}


OUTCOMES-BASED COMMISSIONING FOR SOCIAL CARE IN EXTRA CARE HOUSING: IS THERE A FUTURE?

Introduction

This paper outlines the recent history of strategic and operational commissioning in England followed by a section on outcomes-based commissioning and its relevance for the planning and delivery of care and support to residents in extra care housing.

\section{An overview of a changing world}

As experienced practitioners will be fully aware, there have over the last 25 years been dramatic changes to the role of commissioners of adult social care. Following the NHS and Community Care Act 1990, the development of the internal market and the purchaser/provider split led to a proliferation of providers from outside the state sector. The core function of local authority based commissioners for adult social care was to secure/procure contracts based on competitive tendering between care providers, a mixed economy of care. Block contracts were awarded where relevant services were delivered in an efficient and acceptable time frame. Emphasis was also placed on joint commissioning and pooling budgets between health and social care as a means for more effective and integrated service delivery.

In the closing years of the $20^{\text {th }}$ Century, the advent of a New Labour government with a modernisation strategy (Department of Health, 1998) resulted in further marketisation of service provision plus a demand for a better understanding of the local market for adult social care on the part of local authorities. In outlining the extent of commissioning activities, Fiona Richardson (2006) noted "the importance of meeting needs at a strategic level for whole groups of patients/service users and/or whole populations, which distinguishes commissioning from simply contracting for individual services" (www.cat.csip.org.uk/commissioningebook.p.2).

Page | 1 


\section{Strategic Commissioning}

Strategic commissioning in its early stages focused on how information about local populations and other data sets could be used to provide an efficient service, using eligibility criteria for allocating the resources available. "Managing the market to ensure the right mix and pattern of services to meet statutory guidelines and local objectives within the resources available is the holy grail of commissioners"(Richardson, 2006, p.2). The Institute of Public Care at Oxford Brookes University produced a framework for commissioning based on four elements (analyse the what, plan the how, do the transformation, review the results) (Richardson, 2006, p.4). The activities listed under the four headings did not prioritise the voice of the (potential) service user, even though personalisation became a mainstream policy in 2007(Department of Health, 2014, p.42). This tension between organisational priorities and the wants and needs of service users and carers recurs in the pages of this paper, as do the problems of integrating housing, health and social care addressed in policy documents in the early years of the $21^{\text {st }}$ century (Department of Health, 2004; Department for Communities and Local Government/Department of Health/Department for Work and Pensions, 2008), problems which are yet to be resolved (National Audit Office, 2017; House of Commons Communities and Local Government Committee, 2017).

The global financial crisis that emerged towards the end of the UK's New Labour administration was addressed by the successor Conservative-Liberal Democrat coalition government in the form of an overriding ideological commitment to reducing the role of the state, in part by eliminating the budget deficit (Clarke and Newman, 2012), including major reductions in central government funding for local authorities, where adult social care was one of the core services affected. In response to the financial pressures, local authorities (as well as other agencies) were required to do "more with less", to use scarce resources more effectively and to identify other ways of providing services to those eligible for state support.

Page | 2 
Strategic commissioning, therefore, became a more complex operation as sources of data had to reflect the variety of the wishes of service users (supported or self-funded), be they the increasing numbers of frail older people, people with physical or learning disabilities, people with mental health problems or people needing other kinds of care and support, such as refugees. Existing data sets such as Joint Strategic Needs Assessments needed to be supplemented to support commissioning plans and the implications for service providers were profound. "High quality commissioning and high quality work force commissioning focuses on citizenship, health and wellbeing, achieving good outcomes with people and using evidence, local knowledge, skills and resources to best effect". (Skills for Care, 2015, p.3). At the same time, the call to do "more with less" was linked to longstanding debates about the practical effectiveness or otherwise of joint commissioning (Means and Smith, 1994) or integration of health and social care (Cameron and Lart, 2003). The requirement for joint strategic commissioning through the newly created Health and Wellbeing Boards in April 2013 added to the complexity.

The Care Act 2014 is intended to facilitate wider reform of care and support by making more efficient use of resources, requiring local authorities to promote wellbeing (including the suitability of living accommodation), improve preventative services, enhance effective information and advice services, develop better support for carers and promote integrated care and co-production, all in the context of outcomes focused care and support. "The focus of high quality commissioning is on local people, health and wellbeing, achieving good outcomes with people using evidence, local knowledge, skills and resources to best effect" (Local Government Association et al, 2015). Statutory guidance on the implementation of the Care Act measures, first published in June 2014, referred to housing being "a crucial health-related service which is to be integrated with care and support and health services to promote the wellbeing of adults and carers" (Department of Health, 2014, para.15.50). Revised editions have appeared regularly in subsequent years, reflecting initiatives such as the transfer of funds from the NHS to local authorities through the Better Care Fund, the 
postponement of social care funding reforms until 2020 and the announcement in the November 2015 Spending Review of a new power for local authorities to add a 2\% precept to council tax to provide extra funding for adult social care. The importance of investing in a good quality workforce by enhancing the skills of care managers and social workers as well as commissioners formed part of the strategy to improve the overall process of commissioning, delivering and monitoring services (www.skillsforcare.org.uk/Standards-legislation/Care-Act/Care-Act/aspx).

\section{Operational Commissioning}

In parallel with the development of strategic commissioning, another issue was the planning and delivery of personalised services based on the wants or needs of (potential) service users. This was characterised as operational or micro-commissioning. At the same time, in the 1990s, the voice of the user of adult social care services was beginning to be heard more clearly, led by the demands of physically disabled people for greater control over their own lives. In the mid-1990s direct payments to disabled people were introduced and eligibility was later extended to frail older people. In 2006, Richardson, in her introduction to the commissioning ebook, indicated that developing a care package to meet the needs of an individual service user could be referred to as "microcommissioning or care management"(p.2). More emphasis was placed on the voice of the service user through direct payments and individual budgets in a 2005 Green Paper, 'Independence, Wellbeing and Choice' (Department of Health, 2005). "In future, commissioning will need to be done with service users as opposed to for users" (Richardson, 2006, p.9).

In March 2011 the first Adult Social Care Outcomes Framework (ASCOF) was launched by the Department of Health, co-produced with the Association of Directors of Social Services and the Local Government Association. This key tool was intended to transform care and support from simply delivering services to a commissioning strategy that should start from an outcomes perspective. What was it that (potential) service users wanted from adult social care? The discourse of 
personalisation, person-centred care, even personal budgets became dominant (Lewis and Sanderson, 2012), accompanied by recognition that unpaid, informal carers should be better supported to reduce demand on care services on the part of those eligible for support. This eligibility itself tended to become confined to people with substantial or critical needs, thereby ignoring the preventative component of early intervention.

Beyond the rhetoric, models of outcomes-based commissioning at both the strategic and operational levels have been produced and case studies of local initiatives have been published (Lucas and Carr-West, 2012; Lucas and Suherman, 2014; Bolton, 2015; Local Government Association et al., 2015; Local Government Information Unit, 2016). New sets of skills and new kinds of leadership are required. With the further cuts to local government spending announced for 20162020, the picture appears to become more bleak, if we are to believe recent commentaries from interested parties.

In October 2016 the Care Quality Commission (CQC), in its annual state of health and adult social care in England, commented that "the evidence suggests we may be approaching a tipping point" (CQC, 2016, p.4), a sentiment echoed in the 2016 Budget Survey by the Association of Directors of Social Services (ADASS, 2016, p.22). In November 2016 the Local Government Association (LGA) reported that "the situation is now critical and it is no exaggeration to say that our care and support system is in crisis" (LGA, 2016, p.4). Again, in November 2016 the Nuffield Trust, The Health Foundation and The King's Fund jointly issued a statement on health and social care shortly before the government's financial statement. It emphasised that "the urgent priority for the Autumn Statement is to address the critical state of social care" (Nuffield Trust et al., 2016, p.1). The statement by the Chancellor of the Exchequer on 23 November 2016 made no mention of social care, though a small scale funding package was announced by the government towards the end of the year and the Chancellor's March 2017 budget

Page | 5 
following three years (subsequently changed to $f 3$ billion over the following two years). Meanwhile, a major policy review by the Cabinet Office of social care funding, delivery and integration was announced in January 2017 focusing on medium and long term change, including the commissioning of services.

\section{Outcomes-Based Commissioning and Social Care: Rhetoric vs. Reality}

Early references at national level to a non-process-focused outcomes-based approach in social care can be found in the "modernising" documents produced by the New Labour government, summarised in the 2005 Green Paper. "We propose clear outcomes for social care derived from what people tell us they want". (Department of Health, 2005, p.10). In part, this Command Paper reflected the extensive work of the Social Policy Research Unit (SPRU) at the University of York on outcomes in social care practice (Qureshi et al, 1998; Qureshi, 1999; Qureshi, 2001; Nicholas et al, 2004).

Another overview of developing ideas about an outcomes based approach appeared in 2005 (Sawyer, 2005) noting that, at this early stage, no systematic analysis of outcomes-based initiatives had been undertaken. The Commissioning ebook was published by the Care Services Improvement Partnership (CSIP) in 2006 and in Chapter 9 Andrew Kerslake listed some potential benefits of an outcomes-based approach. According to Kerslake, if fully adopted, it should mean a better service for the user, good provider-commissioner relationships, better understanding of which practices best lead to desired outcomes, unambiguous focus on the purpose of the initiative at both the broad and individual levels and an overall positive motivating effect of an outcomes-based focus.

In 2006, the Social Care Institute for Excellence (SCIE) published an evidence-based paper on outcomes-focused services for older people (Glendinning et al, 2006) which both drew on the 
studies undertaken at SPRU and elsewhere over the previous decade, used the results of a postal survey of outcomes-focused services (mainly recent developments in local authority social services departments) and six case studies "where outcomes-focused approaches were well established" (op.cit., p.x). Overall, from the postal survey it was too early to judge success or failure. From the case studies, it was concluded that outcomes based approaches were aided by reference to outcomes in national publications such as the 2005 Green Paper on adult social care cited above, by local leadership and regular staff training, by local partnerships with bodies beyond the remit of social care and by investment in outcomes when developing new services such as intermediate care. Factors thought to be blocking outcomes-based commissioning included the Single Assessment Process, traditional performance indicators, resource limitations, user and carer reservations and reluctance to embrace innovation on the part of staff at all levels.

Think Local, Act Personal (an organisation committed to personalisation, user-led and communitybased support) also contributed to thinking about the transformation of care and support through an outcomes-based approach. Slasberg (2009) recognised the benefits of a successful transition but noted that the process was full of challenges and difficulties, not least for the social care workforce and back office functions like legal and financial services. Other authors hold similar views (Glendinning et al, 2008; Cairncross, 2009; Institute of Public Care, 2009). By the end of the first decade in the 21 st century and in the midst of a major recession, much had been written but real progress had been modest. Rigorous evaluation was needed to understand the long term consequences of a sustained move to an outcomes based approach (Kneale, 2011).

Moving to more recent times, commentaries on outcomes-based commissioning (OBC) vary from sceptical academic arguments (Bovaird and Davies,2011; Bovaird et al. 2014; Billings and de Weger, 2015) to enthusiastic proponents of a strategy, such as the Mears Group ${ }^{1}$ in relation to domiciliary care. What both sides have in common is a recognition that describing a desirable state of affairs is 
far from being the same as delivering $\mathrm{OBC}$, not least in terms of the cost implications of moving from a traditional "task and time" approach to an outcomes based system, where the onus is on the provider to take the risk rather than the commissioner of services. This has, at times, led to an unwillingness to bid for contracts or to reports of financial difficulties faced by providers. Proponents of $\mathrm{OBC}$ also note that there is no "one size fits all" model of service delivery to follow in developing an outcomes based approach (Sawyer, 2005). This is made very clear in the nine case studies on social care in the 2012 report by the Local Government Information Unit and the Mears Group (Lucas and Carr-West, 2012). This report also noted that from an initial survey of local government officers and elected members over $90 \%$ were paying providers "according to the time they spend with a service user rather than outcomes" (op.cit., p.2).

In the field of adult social care, the desired outcomes of $O B C$ at the population level are said to be reduced hospital admissions, falls prevention and maintaining/enhancing independence, all seen to be outcomes also desired by individuals (Glendinning et al, 2008), as well as reducing pressures on the public purse. An attempt to provide guidance on outcome measures that reflected these concerns appeared in March 2011 with the publication by the Department of Health of the Adult Social Care Outcomes Framework (ASCOF) co-produced with local government. As noted earlier, the aim was to make ASCOF useful (i) for local people to check on how services were or were not improving, (ii) for local councils to improve standards of care. It was described as a "key tool to track progress locally and nationally towards the transformation of care and support" (Department of Health, 2012, p.2). An outcomes based approach was reinforced by the Care Act 2014 which placed new duties on local authorities to shape the market for adult social care in a way to diversify the range of care and to support providers and products available to those in need of care or support (Department of Health, 2014, pp.41-42, 47-48).

Page | 8 
A widely quoted success story in the application of $O B C$ is provided by Wiltshire County Council through its Help to Live at Home (H2LAH) scheme. In brief, "paying care providers by the results they deliver against agreed outcomes can decrease longer-term costs while improving people's quality of life" (Local Government Association, nd, 2014?). It could also improve the pay and working conditions of care workers, not least by replacing hourly pay rates with a salary. Older people needing support are given a person-centred assessment focusing on outcomes that "leave them able to live well with less care" (op.cit., pp.1-2). This assessment by Customer Care Coordinators, who are not qualified social workers, is followed up by a care plan covering how to achieve the outcomes specified, how long it should take and the cost of the plan. Frequent reviews indicate whether the provider should continue to be paid in full. Of great importance was the reduction in the number of contracts. 90 separate contracts worth $£ 14$ million were reduced to eight outcomes-based contracts with four providers, worth $f 11$ million. Problems in implementing this new approach included the challenge of recruiting capable care workers and moving from hourly pay to a salary based system. High initial as well as the running costs of assessment and monitoring at a time of reducing resources could create problems for other local authorities.

This case study was one of a small number of examples of $\mathrm{OBC}$ in English local authorities featured in an overview of OBC for social care published in 2015 (Bolton, 2015; see also Bolton, 2012). In his introduction to the 2015 report, Bolton commented that there were "limited studies to this approach which has only emerged in the last five years" (op.cit.,p.1) and with respect to Wiltshire he reported that "the service found it difficult to explain the changes to their customers" (op.cit.,p.12). However, in contrast to earlier inspections in 2014 (Millett, 2014), the Care Quality Commission found in 2016 that the service provider, the Mears Group, were delivering a good service. The inspection concluded that "the Help to Live at Home service was safe, effective, caring, responsive and well led" (Mears Group, 2016).

Page | 9 
In 2015, a Department of Health funded enquiry into how to commission for better outcomes in adult social care was published by the Local Government Association (2015) in association with the Department of Health, the University of Birmingham, the Association of Directors of Social Services and the national partnership, Think Local, Act Personal. Nine standards were identified "to achieve improved outcomes for adults using social care, their carers, families and communities" (op.cit., p.5). These nine standards were grouped into three domains but "all elements need to be in place to achieve person-centred and outcomes-focused commissioning" (op.cit., p.7). Like earlier documents, the domains and standards espouse particular values, but, in this case, rather than just describing particular examples of $\mathrm{OBC}$, the document focuses on (i) key strategic documents available at the local level, (ii) how to obtain opinions from frontline staff/service users/carers/local community interests and (iii) how to monitor and evaluate.

What changes might lead more local authorities to embrace $O B C$ in adult social care and encourage providers to be less reluctant? One possibility is the training of staff from local government who have featured prominently in programmes run by the UK government's Commissioning Academy established in 2013 and now outsourced to a single provider, the Public Service Transformation Academy. Secondly, apart from the training of staff, commissioning between housing, care and health could be another mechanism by which to underpin OBC. As well as joint commissioning, developing integrated services to further $\mathrm{OBC}$ could also include joint funding, pooled budgets, lead commissioning and collaborative commissioning (Department of Health, 2014, p.56). Thirdly, the Department of Health could act on the recommendation from the National Audit Office (2016) that it should "improve the evidence on, and understanding of, the relationship between the different ways to commission personalised services for users, and improvements in user outcomes" (op.cit.,p.12). Fourthly, at the local level, support for collaborative training for care workers, better pay structures and strategies for career development could be embedded in a radical move towards OBC. Finally, local politicians could be encouraged to use the experience based on their ward 
surgeries to learn more about the views and priorities of their constituents to add weight to the argument for OBC (Local Government Association, 2012, p.3).

\section{Outcomes-Based Commissioning of Social Care in Extra Care Housing}

To achieve $\mathrm{OBC}$ in the context of extra care housing a different approach is needed on the part of a wide range of stakeholders in the field of adult social care (commissioners themselves, senior managers, social work professionals and care workers, service users, carers and supporters, including independent advocates). In respect of extra care housing, the range extends to developers, housing commissioners, housing managers and housing support workers as well as to primary and acute health administrators and professionals (GPs, public health doctors, nurses, therapists, pharmacists, disability experts). $O B C$ is a subset of the broad category of strategic commissioning and another overlapping feature in this context is joint commissioning, traditionally between health and social care and the delivery of better care and support at or closer to home. It is therefore increasingly the interface between housing and social care/health that is important. In mapping the field of commissioning, it should be noted that, as well as strategic commissioning, which in outcome terms focuses on the preferences of populations in particular localities, there is also micro-commissioning where an individual assessor/care worker aims to identify the priorities and needs as expressed by the (potential) service user and/or carer.

So where does that leave commissioners of adult social care in extra care housing settings? The core issue is that both housing and adult social care are intimately interrelated in this kind of setting, so care commissioners need to understand the worlds of housing commissioners and providers and vice versa (Department of Health, 2004). Integration between housing and social care has not had the kind of publicity or support that has occurred for health and social care. In a scoping review of the literature on housing and adult social care funded by the NIHR School for Social Care Research, Bligh et al (2015) noted that "housing and social care have often existed in separate silos with little 
overlap and some duplication"(p.i) and this was reflected in over a hundred articles, reports and other documents included in the review. One of the gaps in the evidence base was the alignment of housing with the integration of health and social care, a concern expressed by Pannell and Blood(2012)who were disappointed that they "could not find better quantitative data that covered housing, care and support holistically" (p.55). Bligh et al (2015) identified key gaps in relation to "the outcomes of prevention...independent living, integration and cost-effectiveness" (p.ii) but there was not a single specific reference to outcomes based commissioning in the review. However, The Housing and Learning Improvement Network (Housing LIN) has since produced useful technical briefs and viewpoints. One core document (Garwood, 2015), labelled a policy technical brief, offered a comprehensive review of policy changes affecting the commissioning and provision of care and support in housing with care.

As noted earlier, significant changes in the policy environment in recent years have required commissioners to develop new skills and new styles of leadership in a challenging financial context. Garwood briefly covers the role of the commissioner under the heading of "market shaping" in the light of the Care Act 2014. She notes the importance of focusing on outcomes, on understanding the business environment of care providers and recommends A Strategic Housing for Older People Analysis Tool (www.housinglin.org.uk/Topics/browse/HousingExtraCare/ExtraCareStrategy/SHOP/) for use in understanding future housing and care needs for, in this case, older people.

But what skills are required to do this? One experienced commissioner pointed to the commissioning cycle (the Institute of Public Care framework: analysis, plan; do, review). What are the needs in the locality? What is likely to make a difference? How to get that set up? How is it monitored? How is the evaluation used to inform the next cycle? (http://www.betterlivesleeds. wordpress.com/talking-heads/money-matters-with-mick-ward-head-of-commissioning-adult-socialcare). This is a useful framework but what is needed to implement such a strategy? 
The work on outcomes-based commissioning (OBC) by the Mears Group with both individual local authorities and the Local Government Association was outlined in an earlier section of this paper (Lucas and Carr-West, 2012; Local Government Association et al,2015). How does it relate to OBC in the field of housing with care? What is known about the integration of housing and social care in local settings? Drawing on an overview of the limited amount of grey literature on housing and adult social care (Bligh et al, 2015), the broad picture is of recognition of the potential of focusing on outcomes in policy pronouncements on adult social care but little by way of actual outcomes in relation to $\mathrm{ECH}$. Why might this be the case? The appearance of initiatives such as Integrated Care Pioneers (Local Government Association, 2016) and Integrated Care Commissioning (Local Government Association/NHS England, 2016) and the NHS Vanguards (where housing is scarcely mentioned) (NHS England, 2016) plus the requirement to offer to those service users who are eligible personal budgets/direct payments across the board tends to cut across the medium to long term objectives of encouraging adult social care providers to take on the risk of embracing $\mathrm{OBC}$. In addition, the notion of engaging with service users in an outcomes-based approach to the planning and provision of adult social care in $\mathrm{ECH}$ is in part undermined by the changing profile of residents in $\mathrm{ECH}$. However, it is acknowledged that in market terms self-funders looking to purchase "retirement housing" could well play an influential role. The future of ECH as a provider of social housing to highly dependent tenants needs to be sharply distinguished from the outright owners of properties in well-resourced large scale retirement communities who are actively seeking to make a lifestyle choice in later life.

\section{Reflections}

In the last decade or so, arguments for change to the way adult social care should be commissioned have focused on the model of achieving outcomes that satisfy a range of criteria. Financial savings in the context of austerity feature strongly as do the ageing of the population as a whole and the ideas around personalisation of services such that the wants and/or needs of 
(potential) service users and their carers should underpin the definition of successful outcomes. Outcomes-based commissioning, it is argued, can in the medium term also improve the working conditions of front line social care providers. As the delivery of adult social care in England has, for over a quarter of a century, been primarily the responsibility of the private and voluntary sectors, the relationship, even partnership, between local government as commissioners and social care providers is all important (Rubery et al, 2013). The move to outcomes-based commissioning requires careful negotiation, and the official literature (frequently based on the Institute of Public Care commissioning model) was until recently strong on what should be done but less focused on how to achieve the stated goals. However, the results of attempts to make the change have produced case studies indicating that there is more than one way to introduce $O B C$ and the 2015 route map published by the Local Government Association is a helpful document, focusing on the how as well as the why. Nevertheless, resistance to this kind of change has been identified not only among social care front line staff and service users, but also among professionals in other settings, such as housing management as well as back office functions like legal and financial services. The introduction of the National Living Wage did not help adding, as it has, to staffing costs (Gardiner, 2015).

Whilst changes to services such as home care have received quite widespread publicity, including dramatically reducing the number of care providers to make major changes in commissioning/ provider relationships more manageable, it does not easily fit into specialist needs nor the kind of service provided in ECH settings. Micro-commissioning seemed more dominant than strategic commissioning in the development of $\mathrm{ECH}$, not least as over the years the level of care and support required for new arrivals has increased based on the view that it should be less expensive than residential care and would help to sustain an independent outlook on life. Whether financial savings on these grounds will result in extra care dwellings catering for a predominantly local authority supported clientele is very much in doubt. It has led to the view that larger scale 
"retirement villages" are a more attractive proposition for the risk taking developers trying to persuade well off people (self funders) to "rightsize" in a setting with a wide range of lifestyle facilities way beyond the limits of formal adult social care. So it is less than clear whether outcomes based commissioning for adult social care is an appropriate model in practice for supporting the less well off population in need of care and support.

Much could depend on the outcome of the consultation on a new funding model for supported housing due to be implemented by April 2019. "We want the quality of services and a focus on outcome for the people who use them to be at the forefront of supported housing provision" (Department for Communities and Local Government/Department for Work and Pensions, 2016, p.14). This consultation document was not produced in the name of the government department the Department of Health - responsible for the provision of social care for adults in extra care housing.

The roles of commissioners and providers of extra care housing in the future are also likely to be affected by the debate following the publication of the Housing White Paper (Department for Communities and Local Government, 2017) in February 2017.The title of the White Paper, "Fixing Our Broken Housing Market", acknowledges the extent of the housing crisis with soaring house prices and low levels of new build. Both local authorities and housing associations were urged to build more but little by way of extra funds were identified and the main focus was on investment by private developers. In particular, the housing implications of population ageing in England and its great diversity were briefly mentioned (paragraphs 4.42-4.44) but the comments were essentially aspirational rather than concrete proposals. "This was a missed opportunity to put the housing needs of our ageing population, front and centre"(Locking, 2017). Instead, the White Paper stated that local authorities needed to make realistic plans to meet local needs and indicated guidance in the future on the kind of information authorities needed to collect about what people want in later 
life and what housing options were available, covering both new build and refurbishment of existing

\section{stock.}

One response to the White Paper by The Housing and Ageing Alliance(2017)pointed out that "the

development of alternative retirement and supported housing is affected by not only housing and

planning policies, but also a range of other policy areas, including welfare reform, financing of social

care, digital technology, leasehold reform, healthcare and transport"(paragraph 3.4).

The inclusion of welfare reform in this list is highlighted by a preliminary report from the House of Commons Communities and Local Government and Work and Pensions Committees (2017)whose

deliberations on the Future of Supported Housing were cut short by the announcement of a general

election on 8 June 2017. This early report queried the viability of the proposed new Local Housing

Allowance funding model for supported housing to be implemented in April 2019 and suggested

Supported Housing Allowance scheme that would reflect the diversity of provision.

n these recent policy commentaries, outcomes-based commissioning (OBC) does not feature but

the thrust of the debate indicates that the place of $\mathrm{OBC}$ in the provision of social care in extra care

housing is not at the core of the government's proposals on housing in general nor supportec

housing in particular.

Notes

1. The Mears Group is one of the UK's major domiciliary care providers delivering services to more than 20,000 people per week in their own homes.

Page | 16 


\section{References}

Association of Directors of Social Services (2016) ADASS Budget Survey 2016, London: ADASS, 22pp.

Billings, J. and de Weger, E. (2015) "Contracting for integrated health and social care: a critical review of four models", Journal of Integrated Care, Vol.23, Issue 3, pp.153-175.

Bligh, J., Cairncross, L. and Porteus, J. (2015) Housing and Adult Social Care, London: NIHR School for Social Care Research, London School of Economics, 72pp.

Bolton, J. (2012) Wiltshire Council: Help to Live at Home Service - An Outcomes-based Approach to Social Care, Case Study Report, Oxford: Institute of Public Care, Oxford Brookes University, April, 21pp.

Bolton, J. (2015) Emerging Practice in Outcome-Based Commissioning for Social Care, Oxford: Institute of Public Care, Oxford Brookes University, April, 23pp.

Bovaird, T., Briggs, I. and Willis, M. (2014) "Strategic commissioning in the UK: service improvement cycle or just going round in circles?", Local Government Studies, Vol.4, No.4, pp.533-559.

Bovaird, T. and Davies, R. (2011) "Outcome-based service commissioning and delivery: does it make a difference?", Chapter 7 in S. Groeneveld and S.van de Walle (eds) New Steering Concepts in Public Management, Vol.21: Research in Public Policy Analysis and Management, Bingley: Emerald Group Publishing, pp.93-114.

Cairncross, L. (nd, 2009?) Outcome Based Commissioning and Contracting, Dartington: Research in Practice for Adults, 16pp.

Cameron, A. and Lart, R. (2003) "Factors promoting and obstacles hindering joint working: a systematic review of the research evidence", Journal of Integrated Care, Vol.11, Issue 2, April, 9-17.

Care Quality Commission (2016) The State of Health and Adult Social Care in England 2015/16, House of Commons Paper (2015-16) 706, 12 October, 146pp.
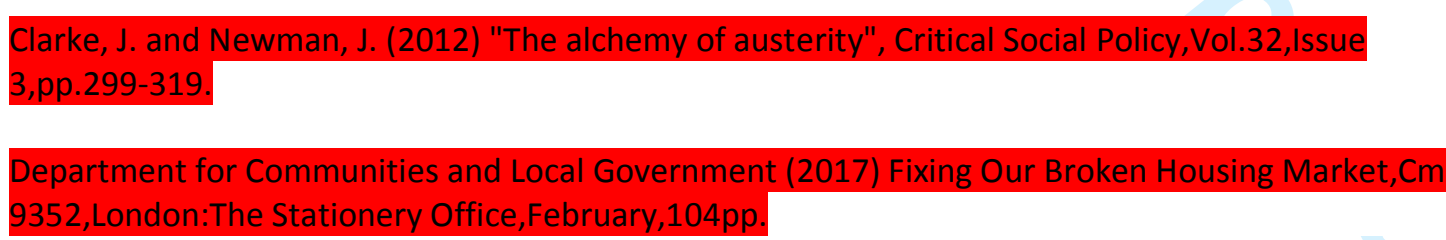

Department for Communities and Local Government/Department of Health/Department for Work and Pensions (2008) Lifetime Homes, Lifetime Neighbourhoods: A National Strategy for Housing in an Ageing Society, London: DCLG, 176pp. 
Department for Communities and Local Government/Department for Work and Pensions (2016) Funding for Supported Housing: Consultation, London: DCLG, November, 24pp.

Department of Health (1998) Modernising Social Services: Promoting Independence, Improving Protection, Raising Standards, Cm 4169, London: The Stationery Office, November, 130pp.

Department of Health (2004) Extra Care Housing for Older People: An Introduction for Commissioners, London: Department of Health, January, 40pp.

Department of Health (2005) Independence, Well-being and Choice: Our Vision for the Future of Social Care for Adults in England, Cm, 6499, London: The Stationery Office, 21 March, 89pp.

Department of Health (2012) The Adult Social Care Outcomes Framework 2013/14, London: Department of Health, 43pp.

Department of Health (2014) Care and Support Statutory Guidance: Issued under the Care Act 2014, London: Department of Health, October, 499pp.

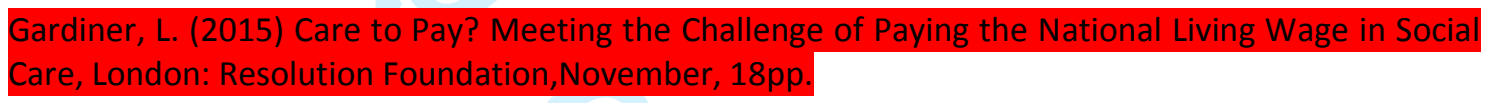

Garwood, S. (2015) Care and Support in Housing with Care for Older People, Policy Technical Brief: Housing LIN, October, 31pp.

Glendinning, C., Clarke, S., Hare, P., Kotchetkova, I., Maddison, J. and Newbronner, L. (2006) Outcomes-Focused Services for Older People, London: Social Care Institute for Excellence, December, 134pp.

Glendinning, C., Clarke, S., Hare, P., Maddison, J. and Newbronner. L. (2008) "Progress and problems in developing outcomes-focused social care services for older people in England", Health and Social Care in the Community, Vol.16. No.1, pp.54-63.

House of Commons Communities and Local Government Committee (2017) Adult Social Care, House of Commons Paper (2016-17) 1103, 27 March, 88pp.

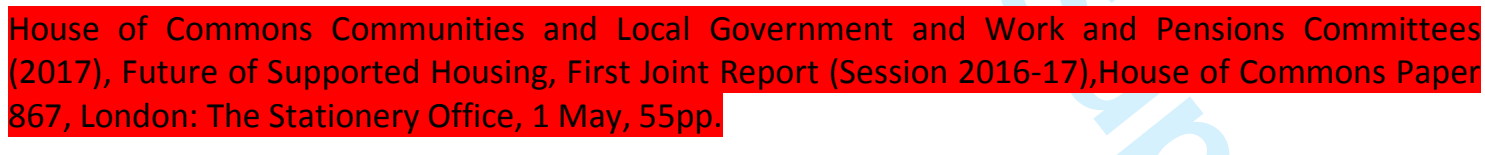

Housing and Ageing Alliance (2017) Response to Department for Communities and Local
Government's Housing White Paper: Fixing Our Broken Housing Market, Nottingham: The Alliance,
April, 10pp.

Institute of Public Care (2009) Changing the Currency of Commissioning from Outputs to Outcomes, Paper 4, Transforming the Market for Social Care, Oxford: Institute of Public Care, Oxford Brookes University., June, 38pp.

Kerslake, A. (2006) "The purchasing process: an approach to outcomes-based commissioning and contracting", The Commissioning ebook, Chapter 9 (www.cat.csip.org.uk/commissioningebook).

Kneale, D. (2011) Establishing the Extra in Extra Care: Perspectives from Three Extra Care Housing Providers, London: ILC-UK, September, 153pp.

Page | 18 


\section{Lewis, J. and Sanderson, H. (2012) A Practical Guide to Delivering Personalisation: Person-Centrec} Practice in Health and Social Care, London: Jessica Kingsley, 240pp

Local Government Association (2012) Commissioning for Better Public Services, London: Local Government Association, July, 11pp.

Local Government Association (nd, 2014?) Case Study: Wiltshire Council: Championing Independence, London: Local Government Association, 4pp.

Local Government Association (2016a) Integrated Care and Support Pioneers, London: LGA, 28 January, 4pp.

Local Government Association (2016b) Adult Social Care Funding: 2016 State of the Nation Report, London: LGA, November, 33pp.

Local Government Association, Association of Directors of Social Services, Department of Health, Think Local Act Personal and the University of Birmingham (2015) Commissioning for Better Outcomes: A Route Map, London: Local Government Association, 44pp.

Local Government Association/NHS England (2016) Integrated Personal Commissioning: Emerging Framework, Leeds: NHS England, May, 24pp.

Local Government Information Unit (2016) Achieving Outcomes Based Commissioning in Home Care, London: LGIU, 9pp.

\section{Locking, R. (2017) Housing White Paper: Ageing Should Have Been Front and Centre, London: Centre for Ageing Better, 13 February, 6pp.}

Lucas, L. and Carr-West, J. (2012) Outcomes Matter: Effective Commissioning in Domiciliary Care, London: Local Government Information Unit and Gloucester: Mears Group, 49pp.

Lucas, L. and Suherman, J. (2014) Commissioning in Adult Social Care: The LGIU and Mears Thought Leader Series-A Summary, London: Local Government Information Unit. April, 50pp.

Means, R. and Smith, R. (1994) Community Care: Policy and Practice, Basingstoke: Macmillan, 277pp.

Mears Group (2016) CQC Rates Wiltshire Conference 'Good’, Gloucester. Mears Group, 3 March.

Millett, T. (2014) "Care Quality Commission: Wiltshire Help to live at home care provider below standard", 3 September (www.marlboroughnewsonlive.co.uk/news/all-the-news/3404)

National Audit Office (2016) Personalised Commissioning in Adult Social Care, House of Commons Paper (2015-16) 883, 3 March, London: The Stationery Office, 50pp.

National Audit Office (2017) Health and Social Care Integration, House of Commons Paper (2016/17) 1011, 8 February, London: The Stationery Office, 56pp.

NHS England (2016) New Care Models: Vanguards - Developing a Blueprint for the Future of NHS and Care Services, September, 64pp (www.england.nhs.uk/vanguards). 
Nicholas, E., Qureshi, H. and Bamford, C. (2004) Outcomes into Practice, York: Social Policy Research Unit, University of York, 152pp.

Nuffield Trust, The Health Foundation, The King's Fund (2016) The Autumn Statement: Joint Statement on Health and Social Care, November, London: The King's Fund, 21pp.

Pannell, J. and Blood, I. (2012) Supported Housing for Older People in the UK: An Evidence Review, York: Joseph Rowntree Foundation, 68pp.

Qureshi, H. (1999) "Outcomes of social care for adults: attitudes towards collecting outcome information in practice", Health and Social Care in the Community, Vol.7, No.4, pp.257-265.

Qureshi, H., Patmore, C., Nicholas, E. and Bamford, C. (1998) Outcomes in Community Care Practice. Overview. Outcomes of Social Care for Older People and Carers, Report No.5, York: Social Policy Research Unit, University of York.

Qureshi, H. (ed.) (2001) Outcomes in Social Care Practice, Report No.7, York: Social Policy Research Unit, University of York, 300pp.

Richardson, F. (2006) "Introduction" in Care Services Improvement Partnership, Commissioning ebook, London: Department of Health Change Agent Team, March, 11pp.

Rubery, J., Grimshaw, D. and Hebsom, G. (2013) "Exploring the Limits to Local Authority Social Care Commissioning: Competing Pressures, Variable Practices and Unresponsive Providers", Public Administration, Vol.91, No.2, pp.419-437.

Sawyer, L. (2005) "An outcome-based approach to domiciliary care", Journal of Integrated Care, Vol.13, Issue 3, pp.20-25.

Skills for Care (2015) Workforce Shaping and Commissioning for Better Outcomes, Leeds: Skills for Care, 30pp.

Slasberg, C. (2009) Outcomes Working and Strategic Commissioning and Contracting, June (www.thinklocalactpersonal.org.uk/asset.?aid=6898), 14pp. 